\title{
Performance and emotionality in the development of behavioral contrast*
}

\author{
GERALD GANNON, TERRANCE NELSON, JOHN E. ROE \\ California State University, Hayward, California 94542 \\ and \\ STEPHEN WINOKUR \\ Texas Christian University, Fort Worth, Texas 76129
}

\begin{abstract}
Three rats were trained to barpress for food on a multiple schedule. One component of the multiple schedule was a FI 2-min schedule. The other component of the multiple schedule was a concurrent FI 2-min FRX schedule. $X$ was constant for each rat, but different between rats. Free shocks were dispensed on a VT 30-sec schedule during the concurrent component. The shocks were "felt" by the rats, but had no effect on behavioral contrast. The data favor emotionality theories over preference theories of behavioral contrast.
\end{abstract}

Currently, two types of theories are claimed to account for the generation of behavioral contrast. Preference, or choice, theories (Bloomfield, 1969; Premack, 1969) emphasize the increased attractiveness of a method of obtaining reinforcement when alternative routes to that reinforcement (schedule components) are blocked or made less effective, more difficult, or more aversive. Emotionality theories (Amsel, 1971; Terrace, 1972) emphasize the response energizing properties of transitory emotional states generated by the inhibition of responding in the presence of one stimulus (the $\mathrm{S}-$ ) of a multiple schedule. Typically response inhibition is produced by a lowering of response rates in one component of a multiple schedule by changing that component to an EXT or long VI schedule (Terrace, 1968). If response and reinforcement rates in the presence of the $\mathrm{S}-$ could be maintained, but the conditions surrounding the $\mathrm{S}-$ be made more aversive, the preference theorist would predict an increase in responding in the presence of the S+. The proponent of an emotionality theory of behavioral contrast would predict that such manipulations would have no effect on behavioral contrast. The experiment reported here sought to determine the outcome of such a situation.

\section{METHOD}

\section{Subjects}

Four male albino rats, obtained from Simonsen Laboratories, were 145 days old at the start of the experiment. The rats were maintained at $85 \%$ of their ad lib weights by controlled feedings of Purina Lab Animal Chow after each 50-min daily session. Water was continuously available in the rats' home cages. No water was available in the experimental space, and each food presentation in the experimental space consisted of a single 45-mg P. J. Noyes Lab Animal Food pellet.

*This research was partially supported by Grant PS 6977 from the Texas Christian University Research Foundation to Stephen Winokur. We thank California State University, Hayward, for the loan of equipment and for technical services. Reprint requests should be sent to Stephen Winokur, Department of Psychology, Texas Christian University, Fort Worth, Texas 76129.

\section{Apparatus}

A Lehigh Valley operant conditioning chamber was the experimental space. The chamber was $9 \mathrm{in.} \mathrm{long,} 8 \mathrm{in}$. wide, and $7.5 \mathrm{in}$. high. The floor of the chamber was composed of 3/32-in.-diam stainless steel rods set 7/16 in. apart and parallel to the front wall of the chamber. A foodcup was centered on the front wall of the chamber, just above the grid floor and a Gerbrands response bar was mounted above the foodcup, 2.5 in. above the grid floor.

A force of $15 \mathrm{~g}$ was required for the operation of the microswitch attached to the response bar. The chamber was enclosed in a sound-deadening plywood box equipped with a ventilating fan. Two clear No. 1819 lamps were mounted $2.25 \mathrm{in}$. from each side of the rear wall and $4 \mathrm{in}$. above the floor of the chamber. A third lamp of this sort was mounted 2 in. above the center of the response bar. The sound pressure level measured at the foodcup was approximately $85 \mathrm{~dB}$; this sound level was in effect when both of the auditory stimuli used in the experiment, viz, white noise and a $1-\mathrm{kHz}$ tone, were presented. Grason-Stadler electromagnetic programming and counting equipment was used to control the experiment and record the data.

Unscrambled electric shocks were generated by an Applegate constant current stimulator and were 100 microA in intensity and $0.1 \mathrm{sec}$ in duration. The "hot" side of the stimulator was connected to alternate bars of the grid floor, while the remaining half of the bars were grounded. The wall of the chamber and the response bar were also grounded.

\section{Procedure}

All rats were adapted to the chamber, accustomed to eat from the foodcup, shaped to barpress, given 100 continuous reinforcements, allowed to barpress on FI 10-sec, FI 35-sec, and FI 1-min schedures of reinforcement, successively, before the start of the experiment proper. For Rats 6 and 7, illumination of the lamps in the chamber and presentation of the white noise constituted the $\mathrm{S}+$, the tone and unlit lamps were the $\mathrm{S}-$. For Rats 8 and 13, the lights and noise were the $S-$, whereas the darkened chamber and tone were the S+. S+ and S- periods were $2.5 \mathrm{~min}$ in duration and followed each other in simple alternation.

In the first phase of this experiment, all rats received food for barpressing on a FI 2-min schedule in the presence of both S+ and $\mathrm{S}-$ for 33 sessions. During the second, baseline, stage of the experiment, a fixed-ratio requirement was added to the fixed-interval requirement in effect during $\mathrm{S}_{-}$- presentations. 


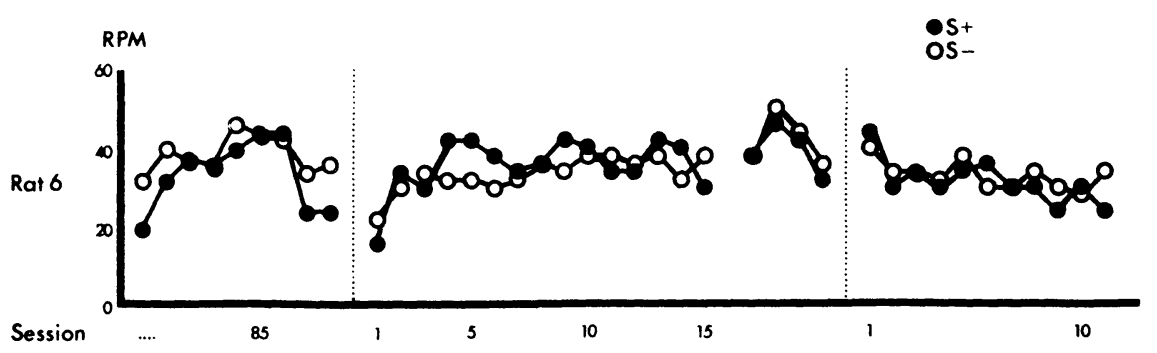

Fig. 1. Rates of barpressing in responses

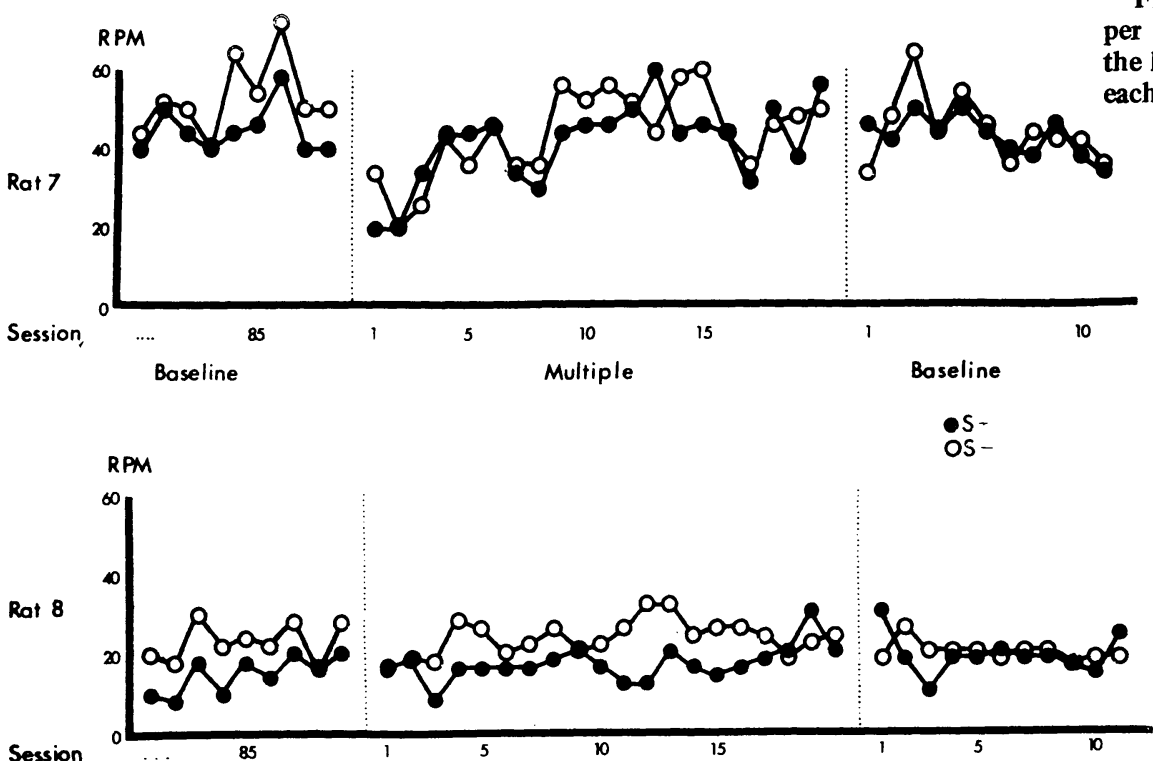

Fig. 2. Rates of barpressing in responses per minute (RPM) for Rats 8 and 13 during the last 10 days of the baseline phase and on each day of the experiment thereafter.

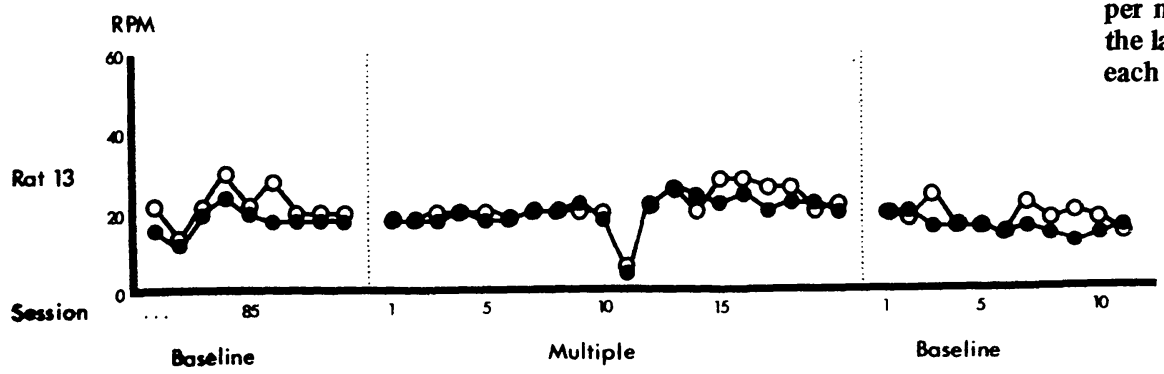

The schedule was then mult (FI 2) (conj FI 2 FR X). The value of $X$ was altered from day to day until response rates in both compartments of the multiple schedule were stable. Then the fixed-ratio parameter, $X$, remained unchanged for a minimum of 20 days. The value of $X$ was $36,20,12$, and 15, for Rats $6,7,8$, and 13 , respectively. The total duration of the baseline phase was 55 days.

During the following 20 days, a more complex multiple schedule was created by dispensing free shocks on a VT 30-sec schedule during $\mathrm{S}-$ presentations. During this phase, all other aspects of the procedure were the same as those in effect during the baseline phase. The complex multiple schedule procedure was succeeded by a return to the procedures of the baseline phase for a period of another 20 days.

\section{RESULTS AND DISCUSSION}

Figures 1 and 2 display rates of responding, in responses per minute (RPM), of each rat in this experiment. To conserve space, only the last $\mathbf{1 0}$ days of the baseline phase are shown.
Response rates during $\mathrm{S}+$ and $\mathrm{S}$ - presentations were stable and about equal in the case of each rat. Response rates during the portion of the baseline stage shown in Figs. 1 and 2 are representative of the response rates displayed throughout prior portions of the experiment proper.

Introduction of free shocks in the procedure labeled Multiple in Figs. 1 and 2 produces very little, if any, change in responding. Some small decline in response rates may have occurred on the first day of this procedure, but response rates rapidly recovered their baseline values. No difference between rates of responding in the presence of the $\mathrm{S}+$ and $\mathrm{S}$ - is apparent. Although the shocks had no effect on the rats' barpressing behavior, it should not be assumed that they were without any behavioral effects. Observation of all animals indicated that shock delivery was followed by vocalization, short pauses in barpressing, and then bursts of rapid pressing. The return to the conditions of the 
baseline phase confirms the absence of any systematic effects of shock presentation on barpressing during the complex multiple phase of this experiment.

These results appear to be incompatible with theories that emphasize preference or choice (Premack, 1969; Bloomfield, 1969) in the generation of behavioral contrast. Theorists who ascribe behavioral contrast to relatively labile emotional effects of nonreinforcement or withholding of responding (Amsel, 1971; Terrace, 1972) will find these data comforting.
H. Kendler and J. T. Spence (Eds.), Essays in neobehaviorism: $A$ memorial volume to Kenneth $W$. Spence. New York: Appleton-Century-Crofts, 1971. Pp. 217-236.

Bloomfield, T. M. Behavioral contrast and the peak shift. In $R$ M. Gilbert and N. S. Sutherland (Eds.), Animal discrimination learning. New York: Academic Press, 1969. Pp. 215-241.

Premack, D. On some boundary conditions of contrast. In J.T. Tapp (Ed.), Reinforcement and behavior. New York: Academic Press, 1969. Pp. 122-147.

Terrace, H. S. Discrimination learning, the peak shift, and behavioral contrast. Journal of the Experimental Analysis of Behavior, 1968, 11, 727-741.

Terrace, H. S. By-products of discrimination learning. In G. H. Bower (Ed.), The psychology of learning and motivation. Vol. V. New York: Academic Press, 1972. Pp. 195-265.

\title{
REFERENCES
}

Amsel, A. Positive induction, behavioral contrast and generalization of inhibition in discrimination learning. In $\mathrm{H}$.

(Received for publication December, 20, 1973.)

Bulletin of the Psychonomic Society

1974, Vol. 3 (4), 277-279

\section{Priming effects on recognition performance*}

\author{
GLEN A. TAYLOR and JAMES F. JUOLA $\dagger$ \\ University of Kansas, Lawrence, Kansas 66044
}

\begin{abstract}
Ss memorized a target list of 40 nouns, half of which were from one semantic category (animals) and the remainder from another (body parts). In a recognition test, Ss were presented with a series of 40 targets (list items) and 40 distractors. Every item in the test sequence was preceded by an item that was either a target or distractor and semantically related (from the same semantic category) or unrelated (from the other category). In addition, any two targets tested in succession were chosen such that half were also adjacent to one another in the memorized list. Thus, half the target items were tested in the same context in which they were studied, and half were not. The results were interpreted in terms of a model that identifies independent encoding and decision stages in recognition memory. Semantic priming apparently facilitated the encoding stage since Ss were faster when successive items were semantically related, but accuracy of recognition was unaffected. Contextual priming effects were independent of semantic priming effects and apparently affected the decision stage of recognition. Providing the same study and test context improved accuracy and resulted in a nonsignificant decrease in response latency.
\end{abstract}

Recognition tests of memory usually begin with the presentation or definition of a target set of items followed by the presentation of test items that include targets and distractors. Performance in such tasks has

*This research was supported in part by funds from Biom edical Sciences Support Grant RR-07037 from the National Institutes of Health, University of Kansas General Research Grant 3294-5038, and Grant MH 24637-01 from the National Institute of Mental Health. The authors thank George Kellas for comments on an earlier draft of this paper.

tRequests for reprints should be sent to Glen A. Taylor, Department of Psychology, University of Kansas, Lawrence, Kansas 66044. been improved by the presentation of priming stimuli immediately before or during the test of target items. For example, target words are recognized more often if the test context is identical to that presented during study (Light \& Carter-Sobell, 1970; Thomson, 1972; Tulving \& Thomson, 1971). These results include, but are not limited to, the use of words semantically related to specific target items as contextual priming stimuli. Semantic priming effects that are independent of any study context have been reported by Meyer and Schvaneveldt (1971; Meyer, Schvaneveldt \& Ruddy, 